\title{
Effect of Temperature on Diffusivity of Monoethanolamine (MEA) on Absorption Process for $\mathrm{CO}_{2}$ Capture
}

\author{
E.E.Masiren, "N.Harun, W.H.W.Ibrahim and F.Adam \\ Faculty of Chemical and Natural Resources Engineering, University Malaysia Pahang, 26300, Kuantan, \\ Pahang, Malaysia \\ noorlisa@ump.edu,my
}

\begin{abstract}
Diffusion coefficient study gains an interest to know the mass transfer properties of molecules especially in study of the absorption process. The main objective of this study is to investigate the effect of temperature on diffusivity of MEA absorption process for $\mathrm{CO}_{2}$ capture. Three different values of process temperature were chosen for simulation in this study, $298 \mathrm{~K}, 313 \mathrm{~K}$ and $318 \mathrm{~K}$. The MD simulation was carried out at NVE (200ps) and NPT (1ns) ensemble in Material Studio 7.0 software. Mean Square Displacement (MSD) analysis was done to compute the self-diffusion coefficient of molecules in tertiary system $\left(\mathrm{MEA}+\mathrm{H}_{2} \mathrm{O}+\mathrm{CO}_{2}\right)$. The results show that the rate of the diffusion coefficient is increased as temperature increased. Diffusion coefficient at $318 \mathrm{~K}$ is the highest compared to others temperature. MD simulation is used to study details about absorption process and capture $\mathrm{CO}_{2}$ acid gases. The simulation diffusivity result obtained from this work shows higher compared with theoretical results.
\end{abstract}

Index Terms- Molecular Dynamic, Simulation, Amine Absorption Process, Monoethanolamine, Carbon Dioxide, Mean Square Displacement.

\section{INTRODUCTION}

Recently, the increment of $\mathrm{CO}_{2}$ composition in air will be contributing the increment of the global temperature. IPCC (Intergovernmental Panel on Climate Change) is an international agency, whose plays a role in preparing a report about the global climate change [1]. IPCC is one of agencies in this world which extensively conduct the research to overcome the global climate change problem. At present, there are many $\mathrm{CO}_{2}$ capturing chemical materials are known such as amine-solvent, organic molecular cages, ionic liquids, metal-organic framework, zeolite and carbon-materials [2]. In this study, amine-solvent is used to determine the diffusivity of $\mathrm{CO}_{2}$ in amine-based absorption process. Absorption process is a process in the scope of post-combustion capture process. This technology has been established over the year since 1930's [3]. MEA, monoethanolamine $\left(\mathrm{C}_{2} \mathrm{H}_{7} \mathrm{NO}\right)$ is a primary amine. Which has been used as solvent in $\mathrm{CO}_{2}$ capture due to higher performance in the absorption process [4].

Molecular Dynamic (MD) simulation was run on molecules species to calculate the diffusion coefficient. This computational method has become an effective tool to explore more deeply about absorption process and also $\mathrm{CO}_{2}$ capture. MD simulation used to study the molecular properties such as the diffusion coefficient [5]. This computation technique can also study others thermodynamic condition at atomic level that cannot be study by doing experimental. Moreover, this technique has many advantages compare to chemical experimental study such as environmental friendly and money saving [6]. In $\mathrm{CO}_{2}$ capture cost process, more than half is distributed to the absorbent regeneration part [7]. Study on the thermodynamic properties is essential before operating the absorption process in pilot plant. In addition, cost for experimental research to study the diffusion coefficient is high particularly at operating condition of higher pressure and temperature [8]. Besides that, the equipment used for study diffusion coefficient of solute in liquid solvent in low concentration is expensive. MD simulation also is an option to study the diffusion coefficient of solute in supercritical fluid because it's difficult to run by experimental [9]. Therefore, the computation measurement study offers better approach to do the research on diffusivity.

Factors that affected the diffusion are concentration gradient, pressure gradient and temperature gradient [10]. Diffusion coefficient, density and viscosity are used to calculate the mass transport 
properties of molecule in a system [11]. Diffusion coefficient is usually seen as $\mathrm{D}_{\mathrm{AB}}$ in equation which represent as the flux of a diffusing component $\mathrm{A}$ and $\mathrm{B}$ with unit $\mathrm{m}^{2} / \mathrm{s}$. In MD simulation, mean square displacement (MSD) analysis or the mean square of the distance molecule move is used calculate the rate of diffusion coefficient. The theories which can be used to study MSD analysis are the Fick's laws, Einstein-Smoluchowski theory [5], [12] and the Maxwell-Stefan theory [13]. In MD simulation, the Maxwell-Stefan theory will be used in MSD analysis. This theoretical can be used to calculate the diffusion of mixture system [14]. Besides MSD analysis, velocity auto-correlation function analysis also used to study transport diffusion system [12].

The literature study on diffusion coefficient by using MD simulation is very limited in open literature. Result diffusion coefficients of MEA, $\mathrm{CO}_{2}$ and $\mathrm{H}_{2} \mathrm{O}$ in various systems were reported in the literature such as study diffusion coefficient of $\mathrm{H}_{2}, \mathrm{H}_{2} \mathrm{O}$ and $\mathrm{CO}$ in various $n$-alkanes by using MD simulation [15], calculate diffusion coefficient of pure water by MD simulation [16], calculate diffusion coefficient of MEA, DEA, MDEA and DIPA [17] by experimental, calculate diffusion coefficient of PZ and MDEA by Tylor dispersion method experiment [18].

The temperature and pressure as operating conditions in actual absorption process in pilot plant are in ranges $311 \mathrm{~K}-333 \mathrm{~K}$ and $1 \mathrm{bar}$, respectively [19]. The aim of this paper is to discuss the effect of temperature on diffusivity of $\mathrm{CO}_{2}$ and MEA in MEA solution during absorption process.

\section{SIMULATION METHODOLOGY}

MD simulation was done by using software of Material Studio (version 7.0) which installed on HP Z420 workstation. This software is licensed software manufacture by Acceryls (San Diego, USA) [20]. The MD simulation was started with replicate the structure of single molecule. The structure of molecules was obtained from Royal Society of Chemistry database [21]. There are three phases in running MD simulation which are the relaxing phase, the equilibrium phase and the sampling phase [5]. Geometry optimization step were carried out on each of the molecules to ensure the stable molecular geometry to be used in further simulation steps. The default algorithm used is the Smart Algorithm and Fine convergence level. The simulation boxes are developed using the amorphous cell calculation model in Material Studio software. Type of forcefield used is COMPASS and summation method used is Ewald to calculate electrostatic energy or electrical interaction [22]. Once the simulation box is developed, this model is simulated for box energy minimization. The simulation is started with equilibration of the system under constant number moles, volume and energy (NVE) ensemble for $200 \mathrm{ps}$ with random initial velocities. The simulation process is continued in dynamic mode under constant number of moles, pressure and temperature (NPT), isothermal-isobaric ensemble for $1 \mathrm{~ns}$. Within this time step, the integration of equation algorithm is going through. The time step choose to be used is $1 \mathrm{fs} .1 \mathrm{fs}$ time step is reported to enough for ensure the molecules in amorphous cell box does not overlapping [22]. Pressure is kept constant at 1 atm to achieve an equilibrium density. The simulation box consists of 300 molecules of MEA, 300 molecules of $\mathrm{CO}_{2}$ and 1000 molecules of $\mathrm{H}_{2} \mathrm{O}$. Figure 1 shows the molecular structure of molecules $\mathrm{CO}_{2}, \mathrm{H}_{2} \mathrm{O}$ and MEA. Table 1 shows the simulation parameters to represent MEA absorption process. This study is an the extension of previous study [23]. This model is simulated at three different temperatures, $298 \mathrm{~K}, 313 \mathrm{~K}$ and 318 $\mathrm{K}$.

Table 1 Simulation parameters to represent MEA absorption process at tertiary system

\begin{tabular}{|c|c|c|c|c|c|}
\hline \multirow{2}{*}{ System } & \multirow{2}{*}{$\begin{array}{l}\text { Number of } \\
\text { Molecules }\end{array}$} & \multicolumn{3}{|c|}{ Density (g/ml) } & \multirow{2}{*}{ Box size $A \times B \times C$} \\
\hline & & $298 \mathrm{~K}$ & $313 \mathrm{~K}$ & $318 \mathrm{~K}$ & \\
\hline MEA & 300 & \multirow{3}{*}{0.989} & \multirow{3}{*}{0.972} & \multirow{3}{*}{0.967} & \multirow{3}{*}{$43 \AA$ x $43 \AA$ x $43 \AA$} \\
\hline $\mathrm{CO}_{2}$ & 300 & & & & \\
\hline $\mathrm{H}_{2} \mathrm{O}$ & 1000 & & & & \\
\hline
\end{tabular}



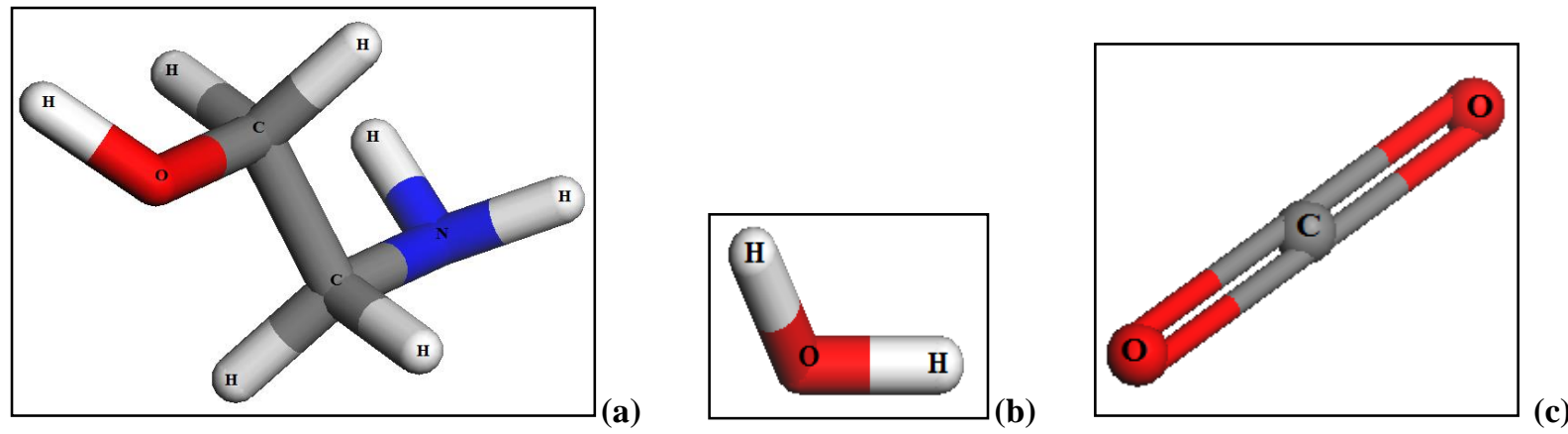

Figure 1 Schematic labeling of molecules (a), Monoethanolamine (b) Water (c) Carbon Dioxide

The Einstein relation is used to calculate MSD in MD simulation. Equation 1 shows equation to determine coefficient of molecular diffusion, D in MD simulation [13]. The slope of MSD graph is diffusion coefficient value, D. The value have divide with 6 as the system is in 3-dimensional system and do conversional unit $\left(\AA^{2} / \mathrm{ps}\right.$ to $\left.\mathrm{m}^{2} / \mathrm{s}\right)$ as shown in equation 1 .

$\mathrm{D}_{\mathrm{i}, \mathrm{self}}=\frac{1}{6 \mathrm{~N}_{\mathrm{i}}} \lim _{\mathrm{m} \cdot \delta \mathrm{t}} \frac{1}{\mathrm{~m} \cdot \delta \mathrm{t}} \sum_{l=1}^{N_{i}}\left[\left(\mathrm{r}_{\mathrm{l}, \mathrm{i}}(\mathrm{t}+\mathrm{m} \cdot \delta \mathrm{t})-\mathrm{r}_{\mathrm{l}, \mathrm{i}}(\mathrm{t})\right]^{2}\right.$

$N_{i}=$ the number of the molecules of component $i$

$\delta \mathrm{t}=$ the time step used in the simulation

$\mathrm{m}=$ the total number of the time steps

$\mathrm{r}_{1, \mathrm{i}}(\mathrm{t})=$ the position of the $l$ th molecule of component $I$ at time $t$

The Stokes-Einstein relation also can be used in calculation of MSD. Equation 2 shows the Einstein equation over the time interval [24]:

$6 \mathrm{Dt}=<|\mathrm{r}(\mathrm{t})-\mathrm{r}(0)|^{2}>=M S D(t)$

Where $\mathrm{r}(\mathrm{t})=[\mathrm{x}(\mathrm{t}), \mathrm{y}(\mathrm{t}), \mathrm{z}(\mathrm{t})]$ show the coordinates atoms at time $t$. Equation 3 is used to calculate the diffusion coefficient as a function of MSD results [25].

$\mathrm{D}=\frac{1}{6} \frac{\mathrm{d}}{\mathrm{dt}} \operatorname{MSD}(\mathrm{t})=$ constant

\section{RESULT AND DISCUSSION}

MD simulation is used to calculate $\mathrm{CO}_{2}$ and MEA diffusivity in MEA solution [13]. MEA is classified as bases with the presence of nitrogen atom which has unshared electron pair. It is consists of hydroxyl group which help for the solubility in water and amino group is used to assist the alkalinity in water to absorb the acid gas [26].

Table 2 shows the diffusion result in simulation. As shown in Table 2, as temperature increased, the value of diffusion coefficient also increased. Molecule is colliding with each other in periodic boundary, result the repeat motion which called as diffusion. When give a heat, the atom will be vibrational motion and collide with other neighbour atom [27]. Moreover, increasing in temperature condition will be affect the rate constant of reaction [28]

The diffusion coefficient of $\mathrm{CO}_{2}$ is higher than MEA and $\mathrm{H}_{2} \mathrm{O}$ as depicted in Table 2. The molecular mass of MEA, $\mathrm{CO}_{2}$ and $\mathrm{H}_{2} \mathrm{O}$ are 61, 44 and 18, respectively. As the molecular mass (size of the molecule) increase, the diffusion rate will be slower. 
In this simulation, MEA solution is selected as chemical solvent were used to absorb $\mathrm{CO}_{2}$ gas. $\mathrm{CO}_{2}$ gas will diffuse from gas to liquid phase then dissolve in liquid phase to do interaction and reaction [29].

Table 2 Diffusion result for simulation

\begin{tabular}{|c|c|c|c|}
\hline \multicolumn{4}{|c|}{ Simulation } \\
\hline Components/ Temperature & $45^{\circ} \mathrm{C}$ & $40^{\circ} \mathrm{C}$ & $25^{\circ} \mathrm{C}$ \\
\hline $\mathrm{CO}_{2}\left(\mathrm{~m}^{2} / \mathrm{s}\right)$ & $9.0897 \mathrm{E}-09$ & $8.6780 \mathrm{E}-09$ & $7.2200 \mathrm{E}-09$ \\
\hline $\mathrm{H}_{2} \mathrm{O}\left(\mathrm{m}^{2} / \mathrm{s}\right)$ & $6.6975 \mathrm{E}-09$ & $6.6600 \mathrm{E}-09$ & $5.8200 \mathrm{E}-09$ \\
\hline $\mathrm{MEA}\left(\mathrm{m}^{2} / \mathrm{s}\right)$ & $5.2770 \mathrm{E}-09$ & $5.3830 \mathrm{E}-09$ & $4.6400 \mathrm{E}-09$ \\
\hline
\end{tabular}

Figures 2 to 4 shows the plot of the MSD versus time at temperature $318 \mathrm{~K}, 313 \mathrm{~K}$ and $298 \mathrm{~K}$, respectively. These graph used to calculate diffusion coefficient have a straight line with a constant slope. The slope was the MSD value increase linearly with time. From these graphs, can be seen that the slope were increased with the increased of temperature. The results obtain from this work show some different with the theoretical calculation.

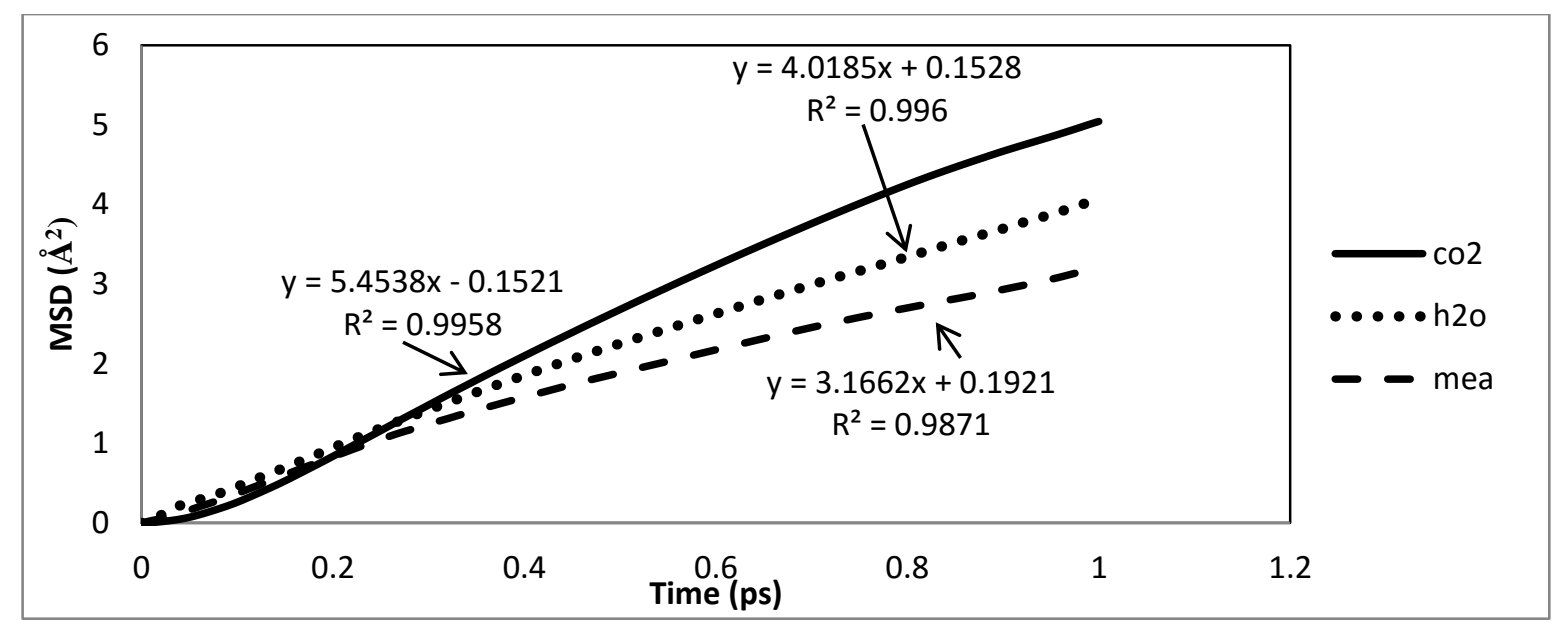

Figure 2 Prediction of diffusion coefficient graph for $\mathrm{MEA}, \mathrm{H}_{2} \mathrm{O}$ and $\mathrm{CO}_{2}$ at $318 \mathrm{~K}$ 


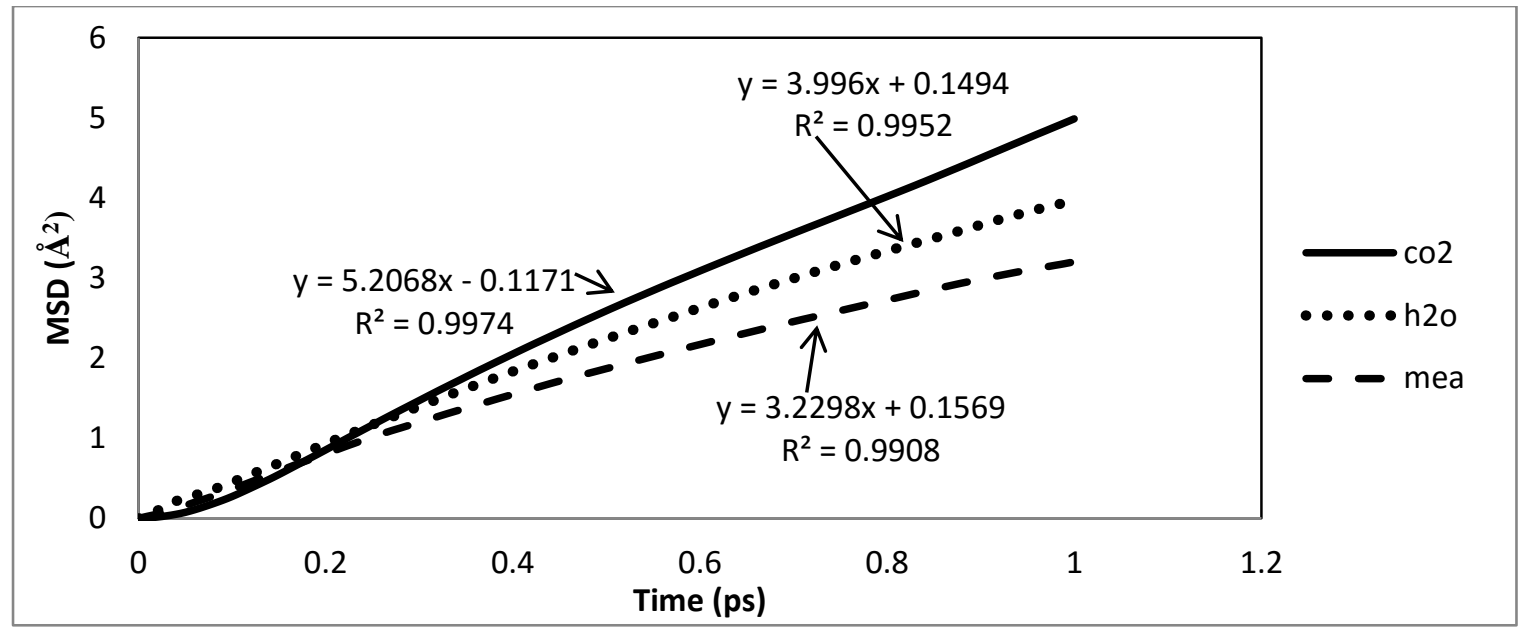

Figure 3 Prediction of diffusion coefficient graph for $\mathrm{MEA}, \mathrm{H}_{2} \mathrm{O}$ and $\mathrm{CO}_{2}$ at $313 \mathrm{~K}$

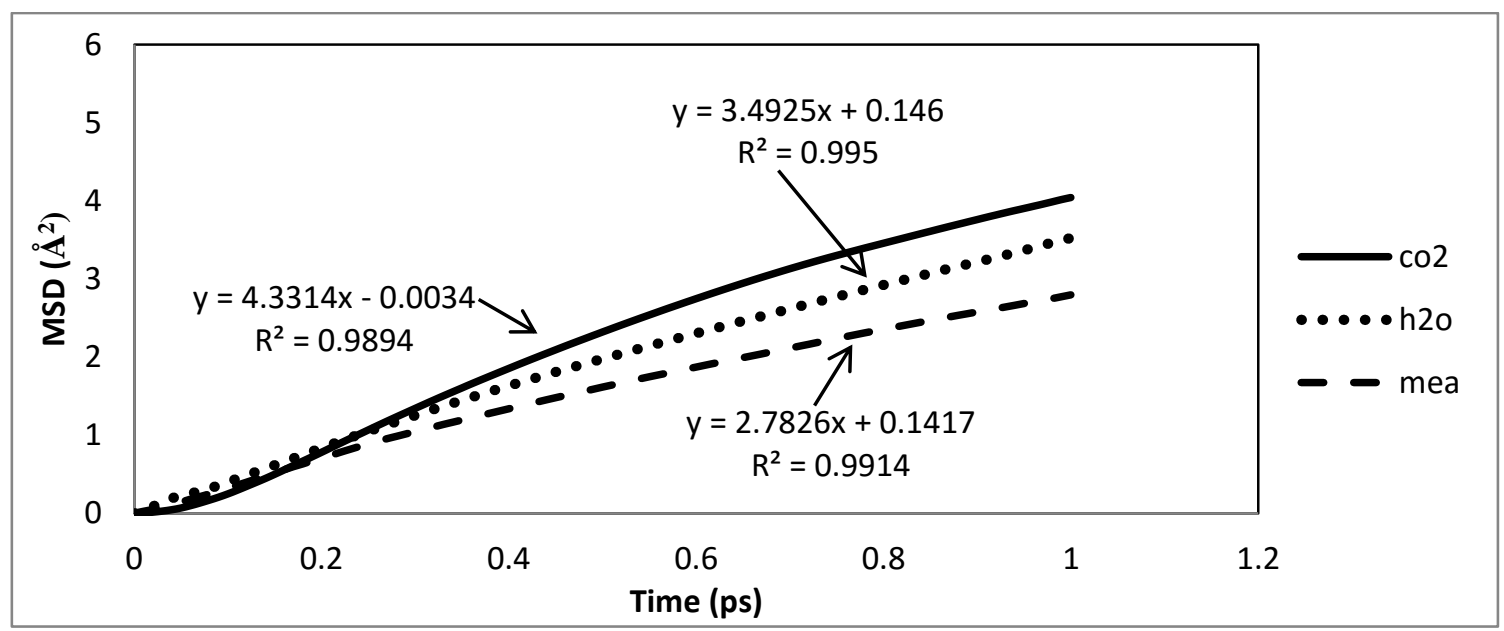

Figure 4 Prediction of diffusion coefficient graph for $\mathrm{MEA}, \mathrm{H}_{2} \mathrm{O}$ and $\mathrm{CO}_{2}$ at $298 \mathrm{~K}$

Compare with mathematical equation

In order to validate the accuracy of simulation result, theoretical calculation is done. Two type of theoretical calculation is used which are Wilke-Chang equation [30] and based on Versteeg and van Swaaij (1988) study [17]. Versteeg and van Swaaij (1988) study is used because related to $\mathrm{CO}_{2}$ diffusion in amine solution.

Theoretical calculation of diffusivities in liquids (Wilke-Chang equation)

The Wilke-Chang equation is used to calculate the diffusivity of MEA and $\mathrm{H}_{2} \mathrm{O}$ [30]. Equation 4 shows the Wilke-Chang equation.

$D_{A B}=1.173 \times 10^{-16}\left(\varnothing M_{A}\right)^{1 / 2} \frac{T}{\mu_{B} V_{A}^{0.6}}$

$M_{A}=$ the molecular weight of solvent B

$\mu_{B}=$ the viscosity of $\mathrm{B}$ 
$V_{A}=$ the solute molar volume at the boiling point

$\varnothing=$ the association parameter for solvent, 2.6 for water

$T=$ the temperature of system

Theoretical calculation of diffusion $\mathrm{CO}_{2}$ in MEA aqueous from Versteeg and van Swaaij (1988)

The diffusion of $\mathrm{CO}_{2}$ in MEA aqueous can be calculate by using the $\mathrm{N}_{2} \mathrm{O}$ analogy in literature [17] [31]. Equations 5 to 9 are shows the way how $\mathrm{CO}_{2}$ diffusivity calculated on aqueous MEA amine.

$$
\begin{aligned}
& D_{\mathrm{CO}_{2}}=D_{\mathrm{N}_{2} \mathrm{O}}\left(\frac{D_{\mathrm{CO}_{2}}}{D_{\mathrm{N}_{2} O}}\right) \text { in water } \\
& D_{\mathrm{CO}_{2}}\left(m^{2} \cdot s^{-1}\right)=2.35 \times 10^{-6} \exp \left\{-\frac{2119}{T(K)}\right\} \\
& D_{\mathrm{N}_{2} O}\left(m^{2} \cdot s^{-1}\right)=5.07 \times 10^{-6} \exp \left\{-\frac{2371}{T(K)}\right\} \\
& D_{N_{2} O}=\left(5.07+0.865 C_{M E A}+0.278 C_{M E A}^{2}\right) \times 10^{-6} \exp \left(\frac{-2371-93.4 C_{M E A}}{T(K)}\right) \\
& C_{M E A}=\frac{10 C_{\%} / w}{M_{w}} \\
& D=\text { the diffusivity } \\
& C=\text { the concentration } \\
& \% w=\text { the percent of weight }
\end{aligned}
$$

Table 3 shows the comparison of simulation results with theoretical results. Based on this Table 3, the value of exponent (E-09) is same for all results. But when compared to diffusivity value, the simulation result is quite larger compared to theoretical results.

The simulation result obtained from this work shows bigger than theoretical result. The reasons are these two systems were different in number of molecules, operating conditions and simulation approximation (force field, summation method, ensemble, algorithm etc.) as previous simulation work. In this simulation work, it applied the molecular mechanics principle. Its means, MD simulation consider the physical interaction and without chemical interaction such in quantum mechanics and experimental study. Furthermore, a reliable result of diffusion coefficient of solutes in solution can be obtained if longer MD simulation need to run expect up to $3 \mathrm{~ns}$ of NPT ensemble [5], $2 \mathrm{~ns}$ of NVT ensemble [22] and $30 \mathrm{~ns}$ of NVT ensemble [15]. [25] Also literature shows the calculation of diffusion coefficient by using numerical computation need to run over a long time periods and/or used large ensemble size for statistical reasons. However, this present simulation work only can be done NPT ensemble part until $1 \mathrm{~ns}$ due to limited time and lower performance of computer processor used. Different type of ensemble for production phase contribute to different result of diffusion coefficient. [12], [22], [9] proposed the simulation procedure by using the canonical equilibrium ensemble (NVT) and [25] used PVT ensemble (the temperature-pressure-volume) in order to compute the diffusion coefficient. 
INTERNATIONAL JOURNAL OF ENGINEERING TECHNOLOGY AND SCIENCES (IJETS) Vol.5 (1) June 2016 DOI: http://dx.doi.org/10.15282/ijets.5.2016.1.6.1045

Table 3 Comparison simulation results with theoretical results

\begin{tabular}{|c|c|c|c|}
\hline \multicolumn{4}{|c|}{ Simulation } \\
\hline Components/ Temperature & $45^{\circ} \mathrm{C}$ & $40^{\circ} \mathrm{C}$ & $25^{\circ} \mathrm{C}$ \\
\hline $\mathrm{CO}_{2}\left(\mathrm{~m}^{2} / \mathrm{s}\right)$ & $9.0897 \mathrm{E}-09$ & $8.6780 \mathrm{E}-09$ & $7.2200 \mathrm{E}-09$ \\
\hline $\mathrm{H}_{2} \mathrm{O}\left(\mathrm{m}^{2} / \mathrm{s}\right)$ & $6.6975 \mathrm{E}-09$ & $6.6600 \mathrm{E}-09$ & $5.8200 \mathrm{E}-09$ \\
\hline MEA $\left(\mathrm{m}^{2} / \mathrm{s}\right)$ & $5.2770 \mathrm{E}-09$ & 5.3830E-09 & $4.6400 \mathrm{E}-09$ \\
\hline \multicolumn{4}{|c|}{ Theoretical (used Wilke-Chang equation) } \\
\hline $\mathrm{CO}_{2}\left(\mathrm{~m}^{2} / \mathrm{s}\right)_{\text {in water }}$ & $3.3893 \mathrm{E}-09$ & $3.1661 \mathrm{E}-09$ & $1.1034 \mathrm{E}-09$ \\
\hline $\mathrm{H}_{2} \mathrm{O}\left(\mathrm{m}^{2} / \mathrm{s}\right)_{\text {in water }}$ & 5.1372E-09 & 4.7989E-09 & 3.3537E-09 \\
\hline $\operatorname{MEA}\left(\mathrm{m}^{2} / \mathrm{s}\right)$ in water & $1.9655 \mathrm{E}-09$ & $1.8360 \mathrm{E}-09$ & $1.2831 \mathrm{E}-09$ \\
\hline \multicolumn{4}{|c|}{ Theoretical (used Versteeg and van Swaaij (1988)) } \\
\hline $\mathrm{CO}_{2}\left(\mathrm{~m}^{2} / \mathrm{s}\right)_{\text {in water }}$ & $3.0001 \mathrm{E}-09$ & $2.6972 \mathrm{E}-09$ & 1.9183E-09 \\
\hline $\mathrm{H}_{2} \mathrm{O}\left(\mathrm{m}^{2} / \mathrm{s}\right)_{\text {in water }}$ & $2.9303 \mathrm{E}-09$ & $2.6013 \mathrm{E}-09$ & $1.7766 \mathrm{E}-09$ \\
\hline MEA $\left(\mathrm{m}^{2} / \mathrm{s}\right)$ in aqueous MEA & $2.2954 \mathrm{E}-09$ & $2.0577 \mathrm{E}-09$ & $1.4467 \mathrm{E}-09$ \\
\hline $\mathrm{CO}_{2}\left(\mathrm{~m}^{2} / \mathrm{s}\right)_{\text {in aqueous MEA }}$ & 2.4002E-09 & 2.1181E-09 & $1.4214 \mathrm{E}-09$ \\
\hline
\end{tabular}

\section{CONCLUSIONS}

Mean square displacement calculation is used to calculate the diffusivity of molecules in MEA solution. The rate of the diffusion coefficient is increased as temperature increased. Rate of diffusion coefficient at $318 \mathrm{~K}$ is the highest compared to $313 \mathrm{~K}$ and $298 \mathrm{~K}$. The diffusion coefficient of $\mathrm{CO}_{2}$ is larger than $\mathrm{H}_{2} \mathrm{O}$ and MEA in liquid state due to small molecular weight. Even though the values of diffusion coefficient of this simulation work are higher than experimental and theoretical data, the trend follows the theoretical with $\mathrm{CO}_{2}$ has the highest diffusion coefficient. While, it is good effort to study the diffusion coefficient by MD simulation. The main reason of different diffusivity value is probably due to MD simulation used molecular mechanic principle that may ignore some factors for cheaper calculation. MD simulation basically involved the physical interaction and based on molecular mechanic principle. Besides that, this simulation is run in condition of $1 \mathrm{~ns}$ NPT ensemble and on lower performance of computer processor. Further study need to carry out in order to study deeply about $\mathrm{CO}_{2}$ absorption in MEA solution.

\section{ACKNOWLEDGEMENTS}

The author would like to give appreciation to University Malaysia Pahang and the Accelrys Asia Pacific for fully cooperate to complete this work. In addition, for financial support from the Higher Education Ministry of Malaysia through fundamental research grant scheme (FRGS) on RDU130109. 


\section{Nomenclature:}

$\begin{array}{ll}\text { ps } & \text { Picoseconds } \\ \text { ns } & \text { Nanoseconds } \\ \text { fs } & \text { Femtoseconds } \\ \text { g/ml } & \text { Grams to milliliters } \\ \text { A } & \text { Angstrom } \\ \mathrm{m} & \text { Meter } \\ \mathrm{s} & \text { Second } \\ \mathrm{E} & \text { Exponential } \\ \mathrm{T} & \text { Temperature } \\ \mathrm{K} & \text { Kelvin } \\ \mathrm{Q} & \text { Heat transfer }\end{array}$

\section{REFERENCES}

[1] F. S. Zeman and K. S. Lackner, "Capturing Carbon Dioxide Directly From The Atmosphere," World Resource Review, 2004; 16(2):157-172, 2004.

[2] J.-J. Chen, W.-W. Li, X.-L. Li, and H.-Q. Yu, "Carbon dioxide capture by aminoalkyl imidazolium-based ionic liquid: a computational investigation.," Physical chemistry chemical physics : PCCP, Apr. 2012; 14(13):4589-96

[3] Arthur Kohl and Richard Nielsen, Gas Purification, Firth Edit. United States of America: Gulf Publishing Company, Houston, Texas, 1993.

[4] L. Dubois and D. Thomas, "Carbon dioxide absorption into aqueous amine based solvents: Modeling and absorption tests," Energy Procedia, Jan. 2011; 4:1353-1360

[5] J. Wang and T. Hou, "Application of molecular dynamics simulations in molecular property prediction II: diffusion coefficient.," Journal of computational chemistry, Dec. 2011; 32(16):3505-19

[6] J. Charpentier, "The triplet 'molecular processes-product-process' engineering: the future of chemical engineering ?," Chemical Engineering Science, Nov. 2002; 57(22-23):4667-4690

[7] F. A. Chowdhury, H. Okabe, H. Yamada, M. Onoda, and Y. Fujioka, "Synthesis and selection of hindered new amine absorbents for $\mathrm{CO}_{2}$ capture," Energy Procedia, Jan. 2011; 4:201-208,

[8] O. A. Moultos, I. N. Tsimpanogiannis, A. Z. Panagiotopoulos, and I. G. Economou, "Atomistic molecular dynamics simulations of $\mathrm{CO}_{2}$ diffusivity in $\mathrm{H}_{2} \mathrm{O}$ for a wide range of temperatures and pressures.," The journal of physical chemistry. B, May 2014; 118(20):5532-5541

[9] Y. A. Hidenori Higashi, Yoshio Iwai, Hirohisa Uchida, "Diffusion Coefficients of Aromatic Compounds in Supercritical Carbon Dioxide Using Molecular Dynamics Simulation," Journal of Supercritical Fluids (S20), 1998; 13(1-3):93-97

[10] B. E. Poling and J. M. Prausnitz, The Properties of Gases and Liquids, Fifth Edit. United States of America: The McGRAW-HILL Companies, 2001.

[11] P.-H. Lin, C.-C. Ko, and M.-H. Li, "Ternary diffusion coefficients of diethanolamine and N-methyldiethanolamine in aqueous solutions containing diethanolamine and $\mathrm{N}$ methyldiethanolamine," Fluid Phase Equilibria, Feb. 2009; 276(1):69-74

[12] L. A. F. Coelho, J. V. Oliveira, and F. W. Tavares, "Dense fluid self-diffusion coefficient calculations using perturbation theory and molecular dynamics," Brazilian Journal of Chemical Engineering, Sep. 1999; 16(3):1-16

[13] Emmanuelle Masy, "Predicting the Diffusivity of $\mathrm{CO}_{2}$ in Substituted Amines," Delft University of Technology, 2013.

[14] Mahmoud Kamal Forrest Aboulnasr, "A Simulation Study of Diffusion in Microporous Materials," University of California, 2013. 
[15] Z. A. Makrodimitri, D. J. M. Unruh, and I. G. Economou, "Molecular simulation of diffusion of hydrogen, carbon monoxide, and water in heavy n-alkanes.," The journal of physical chemistry. B, Feb. 2011; 115(6):1429-39,

[16] Anupan Chatterjee, "Calculation of Self Diffusion Constant of Pure Water Using Molecular Dynamic Simulation,” Indian Institute of Technology, Bombay, 2014.

[17] E. D. Snijder, M. J. M. te Riele, G. F. Versteeg, and W. P. M. van Swaaij, "Diffusion coefficients of several aqueous alkanolamine solutions," Journal of Chemical \& Engineering Data, Jul. 1993; 38(3):475-480

[18] P. W. J. Derks, E. S. Hamborg, J. A. Hogendoorn, J. P. M. Niederer, and G. F. Versteeg, "Densities, Viscosities, and Liquid Diffusivities in Aqueous Piperazine and Aqueous (Piperazine + N -Methyldiethanolamine) Solutions," Journal of Chemical \& Engineering Data, May. 2008; 53(5):1179-1185

[19] C.-H. Yu, "A Review of CO2 Capture by Absorption and Adsorption," Aerosol and Air Quality Research, 2012; 12:745-769

[20] Accelrys, “Accelrys Materials Studio," Accelrys Inc., San Diego, California, 2014; Version 7

[21] "ChemSpider Database," Royal Society of Chemistry, 2014. [Online]. Available: http://www.chemspider.com/.

[22] H. Higashi and K. Tamura, "Calculation of diffusion coefficient for supercritical carbon dioxide and carbon dioxide+naphthalene system by molecular dynamics simulation using EPM2 model," Molecular Simulation, Oct. 2010; 36(10):772-777

[23] E. E. Masiren, N. Harun, W. H. W. Ibrahim, and F. Adam, "The effect of temperature on intermolecular interaction of monoethanolamine absorption process for $\mathrm{CO}_{2}$ removal," 2014; $5(5): 1-4$

[24] A. Einstein, "On The Electrodynamics on Moving Bodies," Annalen der Physik, June $1905 ; 30: 549-560$

[25] R. E. Zeebe, "On the molecular diffusion coefficients of dissolved, and and their dependence on isotopic mass," Geochimica et Cosmochimica Acta, May 2011; 75(9):24832498

[26] P. R. Abharchaei, "Kinetic study of carbon dioxide absorption by aqueous solutions of 2(methyl)-aminoethanol in stirred tank reactor," Chalmers University of Technology, 2010.

[27] J. M. S. May and T. A. Atoms, "Molecular Dynamics Simulations of Phase Transitions," United States of America, 2013.

[28] P. S. Nair and P. P. Selvi, "Absorption of Carbon dioxide in Packed Column," International Journal of Scientific and Research Publication, 2014; 4(4):1-11

[29] N. J. M. C. Penders-van Elk, E. S. Hamborg, P. J. G. Huttenhuis, S. Fradette, J. a. Carley, and G. F. Versteeg, "Kinetics of absorption of carbon dioxide in aqueous amine and carbonate solutions with carbonic anhydrase," International Journal of Greenhouse Gas Control, Jan. 2013; 12:259-268

[30] C. R. Wilke and P. Chang, "Correlation of diffusion coefficients in dilute solutions," AIChE Journal, Jun. 1955; 1(2):264-270

[31] J. Ko, T. Tsai, C. Lin, H. Wang, and M. Li, "Diffusivity of Nitrous Oxide in Aqueous Alkanolamine Solutions," Journal of Chemical \& Engineering Data, Jan. 2001; 46(1):160165 